\title{
The Role of an Interactive Visual Learning Tool and its Personalizability in Online Learning: Flow Experience
}

\author{
Young Ha \\ California State University, Long Beach \\ Hyunjoo Im \\ University of Minnesota, Twin Cities
}

\begin{abstract}
The purpose of this study was to examine the effect of interactive online learning tools on college student learning using flow as the guiding perspective. Study 1 was conducted to test the effect of online interactivity manipulated by dynamic visual learning tools on student's flow experience, level of telepresence, actual performance on tests, and perceived values of such activities. Study 2 was designed to test the effect of personalizability of difficulty levels in the interactive online activity on students' learning experience. The results found that interactive online learning tools can facilitate student's active learning process by increasing attention, curiosity, and interest about the online activity and by reducing awareness of physical surroundings. In addition, the interactive activity significantly improved students' test scores. This study also found that personalized difficulty options available in the interactive online activity significantly increased students' perceived hedonic value (i.e., enjoyment) of and the level of satisfaction with the activity. The results emphasize the critical role of interactive visual learning tools in the online activities in improving students' flow experience and actual performance. Personalizability of task levels is also recommended in online learning activities to increase students' perceived hedonic value and satisfaction with such online activities.
\end{abstract}

Keywords: online learning, interactivity, visual learning tools, persoanalizability, flow, perceived value

Ha, Y. \& Im, H. (2020). The role of an interactive visual learning tool and its personalizability in online learning: Flow experience. Online Learning, 24(1), 205-226. https://doi.org/10.24059/olj.v24i1.1620 


\section{The Role of an Interactive Visual Learning Tool and its Personalizability in Online Learning: Flow Experience}

Online-based learning has become an increasingly common mode of learning in higher education. According to a report by the Babson survey research group (Allen, Seaman, Poulin, \& Straut, 2016), 28.4\% of all enrolled students in higher education took at least one distance learning course in 2014. In the fall of 2016, more than 6.3 million U.S. students took at least one online class (Friedman, 2018). As of 2017, over 700 learning management system suppliers offer products to the growing eLearning market (Jasmini, 2017). Despite the increasing popularity of online learning, online courses in higher education still suffer from high dropout rates (Chen, 2018). Some found the reason to be the lack of interactivity and personalized experience in the context of online learning (Oria, 2017).

With the technology, the online learning environment provides an exciting opportunity to enhance learning experience of learners by offering interactive and personalizable content. As dominant online information is visual (Carroll \& Kop, 2016), properly designing visual learning tools that allow interactive and personalized learning experience can be critical for successful online learning.

Previous research and literature provide support for the importance of interactivity and personalizability in online learning effectiveness. As emphasized by online educators (Moreillon, 2015), interactivity is a key feature of online education which helps attract and retain students in online classes. Interactive online tools provide opportunities for instructors to communicate better with students and enhance students' online learning experience. While the online tools are often adopted to compensate for the loss of face-to-face interaction in a traditional education setting (Sun \& Hsu, 2013), well-designed online tools not only can transfer some face-to-face teaching techniques but also can increase individual students' engagement and motivation to learn. Computer-mediated interactions can elicit students' curiosity and hedonic motivation when the learning material is interactive and engaging (Oudeyer, Gottlieb, \& Lopes, 2016). Kucuk and Richardson (2019) found that a well-designed online learning interface made learners cognitively and emotionally engaged in learning and increased their satisfaction as well.

The theory of flow provides the conceptual framework of why interactive visual learning tools help students engage and actively participate in the learning process (Csikszentmihaly, 1990). The flow theory suggests that interactive visual learning tools have a high potential to engage students in the learning process as students are likely to experience flow and the effect will be greater when the students' skill matches the task difficulty (Csikszentmihaly, Abuhamdeh, \& Nakamura, 2005). Interactive online learning activity with personalizable options enable learners to be more focused and engaged as they can select the learning level that matches their skills (Pandey, 2017). Ou, Joyner, and Goel (2019) also emphasized the critical role of personalized online teaching materials in stimulating learners' interest and engaging them in learning.

While previous research investigated the role of interactivity and flow in learning, a few gaps in the literature call for further investigation. The scope of the online learning literature is mostly focused on the role of human-human interaction (e.g., learner-instructor and/or learnerlearner), limiting our understanding of the human-computer interaction (i.e., learnercontent/interface) effects on online learning. Considering the importance of interface in online learning, Wei, Peng, and Chou (2015) urged need for expanding the scope of interactivity from human-human interaction to human-computer interaction in an online learning environment. The 
current study responds to this call and investigates human-computer interaction effects on online learning. Also, interactivity and flow effects on learning from previous literature have been inconsistent, particularly in the context of internet-based learning environment (Meyer \& Jones, 2013). Such inconclusive findings may be due to the fact that the majority of studies adopted selfreported surveys of learning experience (e.g., Chou, Peng, Chang, 2010; Etemad-Sajadi, 2016; Wei et al., 2015) that are prone to response biases, such as social desirability, memory biases, and an inability to detect causal relationships. In addition, while personalization is hailed as a critically important element of online interface, few scholarly journal articles examined the effect of personalization on students' online learning. To fill the gap in the area of research, the current study aims to understand the causal impact of interactivity and personalization of online visual learning tools on student's learning through a series of experiments. This study focused on understanding two key factors linked to online visual learning tools: interactivity and the balance between skill level and task difficulty (i.e., interactivity with personalizable options). Two experimental studies were conducted to investigate each element. The purpose of Study 1 was to examine the effect of online interactivity on student learning process manifested as flow experience. The focus of Study 2 was to investigate whether students' learning experience is enhanced when students could match their skill level with the task difficulty through personalization options.

\section{Review of Related Literature}

\section{Interactivity in Online Learning}

Previous research (e.g., Cho \& Kim, 2013; Park, 2011; Rodriguez-Ardura et al., 2016; Wei, Peng, \& Chou, 2015) has emphasized interactivity as a critical success factor of online learning because it enhances students' learning experience and their performance. The concept of interactivity used and examined in online learning literature has been varied (Domagk, Schwartz, \& Plass, 2010; Wei et al., 2015). Most common type of interactivity tested in previous online learning research was the effect of human-human interaction on student learning (e.g., Chen, Chang, Ouyang, \& Zhou, 2018; Luo, Zhang, \& Qi, 2017; Kent, Laslo, \& Rafaeli, 2016; Yeh, Rega, Chen, 2019). Human-human interactivity in the e-learning literature reported significant effects of student-instructor communication (Cheng, 2013; Luo et al., 2017: Paechter, Maier, \& Macher, 2010), student-student interaction (Chen et al., 2018; Cheng, 2013; Luo et al., 2017), and peer evaluation (Yeh et al., 2019) on student online learning experience. Researchers have also emphasized the critical role of human-computer interaction in the context of online learning environment (Chou, 2003; Low, Low, \& Koo, 2003; Wei et al., 2015). Previous research on human-computer interactivity were likely to focus on learner-interface interactivity, attempting to understand effects of using various new learning management systems (e.g., Wei et al., 2015). A small number of studies investigated learner-content interactivity that addresses the question of learning-specific online contents such as individualized guides, activities, and instructions.

In this study, learner-content interactivity is of the focal interest and interactivity is defined as a characteristic of an online system that allows a user to modify elements and contents of the online environment in real time (Rodriguez-Ardura \& Meseguer-Artola, 2016) and provides immediate responses to the user's input (Chang \& Wang, 2008). Evans and Sabry (2003) conceptualized a three-way model of human-computer interactivity in computer-mediated learning environment: computer-initiation, learner-response, and computer-feedback. Accordingly, in the 
e-learning environment, students interact with online activities as they respond to the learning activity (e.g., by clicking and moving images, by answering questions, etc.) and get immediate feedback from the activity (e.g., correct answers, tips, and guidance provided). Interactive online learning tools examined in the current study was developed to incorporate this three-way interactivity.

\section{Telepresence}

In the online environment, interactivity is a critical determinant of engagement (Karageorgakis, 2018) because high interactivity of a system allows the users to be fully present in the mediated environment. This feeling or perception of being present in a simulated or mediated environment is called telepresence (Li, Daugherty, \& Biocca, 2002). Telepresence is described as a user's immersive experience in a mediated environment (Steuer, 1992) and sometimes also noted as immersion in the literature (e.g., Carrozzino \& Bergamasco, 2010).

Previous research in the mediated environment found interactivity of an online system is an important predictor of telepresence (Esteban-Millat, Martinez-Lopez, Huertas-Garcia, Meseguer, \& Rodriguez-Ardura, 2014; Li et al., 2002; Lim \& Ayyagari, 2018; Skadberg \& Kimmel, 2004). For example, in a study of online advertisement, participants felt stronger telepresence when the online advertisement was interactive (e.g., Fortin \& Dholakia, 2005). Likely, interactive online features such as clickable images with hyperlinks were found to increase telepresence (Coyle, Mendelson, \& Kim, 2008). Therefore, H1 was hypothesized.

H1: Students who used the interactive visual learning tools will report a higher level of telepresence than those who used the one with noninteractive visual learning tools.

\section{Flow}

Flow is a subjective experience of total immersion in the activity (Csikszentmihaly, 1990) and a momentary feeling of complete engagement (Meyer, Klingenberg, \& Wilde, 2016). Flow is often characterized by simultaneous experience of several dimensions: attention focus (or concentration), positive emotions such as enjoyment, joy, and pleasure, sense of control, distorted sense of time, and reduced awareness of physical surroundings and self (e.g., Rossin, Ro, Klein, \& Guo, 2009). Researchers in human-computer interaction emphasized the role of flow as an important antecedent of learning in an online environment because of the interactive nature of online operations (Hoffman \& Novak, 2009).

Because interactivity increases telepresence, it is likely that high interactivity also increases the flow experience. Hoffman and Novak (2009), after a review of 12 empirical studies using flow theory, reported that interactivity has both direct and indirect effects on flow. Researchers reported empirical evidence of the positive effect of interactivity on flow experience in a web-based training program (Choi, Kim, \& Kim, 2007), e-learning environment (Rodriguez-Ardura \& MeseguerArtola, 2016), and online university courses (Esteban-Millat et al., 2014; Guo, Xiao, van Toorn, Lai, \& Seo, 2016). In online flow experience research, the majority of researchers understood flow as a multidimensional construct and measured these multiple constructs to capture flow (Hoffman \& Novak, 2009). Similarly, in this study, the core elements of the experience of flow is operationalized as (a) control, (b) attention focus, (c) curiosity, and (d) intrinsic interest following the conceptualization of Huang (2003). Therefore, H2 was formulated. 
H2: Students who used the interactive visual learning tools will experience a higher level of flow (control $(\mathrm{H} 2 \mathrm{a})$, attention focus $(\mathrm{H} 2 \mathrm{~b})$, curiosity $(\mathrm{H} 2 \mathrm{c})$, and intrinsic interest $(\mathrm{H} 2 \mathrm{~d})$ ) than those who used the noninteractive visual learning tools.

\section{Interactivity and Learning}

Interactive tools can be effective in facilitating student learning. A range of literature provides evidence that interactivity increases learning measured as test scores, understanding of concepts, retention of information (Evans \& Gibbons, 2007; Wang, Vaughn, \& Liu, 2011), and perceived knowledge gain (Skadberg \& Kimmel, 2004; Sun \& Hsu, 2013).

Interactivity of a tool can positively influence learning for several reasons. Some noted that interactive instructional tools can encourage learners to self-motivate and direct their own learning, consequently increasing learning by actively constructing knowledge (Evans \& Gibson, 2007; Reiter, Lakoff, Trueger, \& Shah, 2013). Others reasoned interactive tools enhance learning because they allow users to control the learning process by engaging in the learning activity at their own pace and by skipping, reviewing, and repeating the content as needed (Wang et al., 2011). Others argued the interactions within the instructional tools help engage learners in the learning process and prolong their concentration on learning (Esteban-Millat et al., 2014; Kiili, 2005). Therefore, H3 was developed.

H3: Students who used the interactive visual learning tools will perform better on a test than those who used the one with the noninteractive visual learning tools.

\section{Utilitarian and Hedonic Value}

Online information tools can provide utilitarian/instrumental value (e.g., useful information to enhance performance efficiency) or hedonic/experiential value (e.g., enjoyment) (van der Heijden, 2004). Researchers emphasized comprehensively understanding both hedonic and utilitarian values (Babin, Darden, \& Griffin, 1994). In the context of learning, utilitarian value refers to the degree to which a tool provides benefits to achieve learning. Hedonic value, on the other hand, is the degree to which a tool provides emotional and entertainment benefits. Previous research emphasized the effect of interactive learning environment on learners' perceived hedonic (e.g., pleasure) and utilitarian (e.g., usefulness) value about online learning (Liaw, 2008; Liaw \& Huang, 2013). Wei et al. (2015) also found that students' perceptions of online learning are highly related to teacher's design of interactive learning activities. Cheng (2013a) who longitudinally examined the effect of interactivity features in the context of e-learning environment found that online interactive features (e.g., responsiveness, personalization, etc.) positively influenced learners' perceived usefulness and enjoyment of e-learning system. Similarly, when the students use an interactive visual learning tool, they are more likely to find the learning tool to be useful and fun because the tool not only effectively provides contents (i.e., utilitarian value) but also inherently possesses the ability to dynamically change in response to the user input. Therefore, $\mathrm{H} 4$ was formulated.

H4: Students who used the interactive visual learning tools will perceive a higher level of utilitarian $(\mathrm{H} 4 \mathrm{a})$ and hedonic value $(\mathrm{H} 4 \mathrm{~b})$ than those who used the noninteractive visual learning tools.

\section{Personalization: Skill-Challenge Level}

Csikszentmihaly et al. (2005) identified three important preconditions for flow experience: clarity of the goal, clear and immediate feedback, and the skill-challenge balance. The interactive 
visual learning tools can be designed to satisfy the first two conditions. The students are usually given a clear objective for learning (i.e., to accomplish the task and learn the materials) and the interactivity provides immediate and clear feedback on the student's input. However, the last condition is dependent on individual student's ability (e.g., prior knowledge). While learning activities are designed to offer a reasonable level of challenge for students, the balance can only be achieved when the students are properly prepared for the given task. According to the model of flow (Csikszentmihaly \& Csikszentmihaly, 1988), when the challenge and skill do not match, the individuals will feel anxiety (low skill-high challenge), boredom (high skill-low challenge) or apathy (low skill-low challenge). In a meta-analysis study of antecedents of flow, Fong, Zaleski, and Leach (2015) found the skill-challenge balance to be a strong antecedent of flow among nine antecedents investigated. Therefore, in order to make students fully engage in online learning and experience flow, the skill-challenge balance should be achieved. Guo and colleagues (2016) empirically showed that the skill-challenge balance positively influenced flow that students experienced during online learning.

While previous studies relied on self-reported perception of skill/challenge balance by measuring either perceived skill/challenge level and comparing two scores to determine the balance (e.g., Fullagar, Knight, \& Sovern, 2013) or measuring the perceived balance itself (e.g., Engeser \& Rheinberg, 2008), the current study attempted to achieve the balance by providing varying degrees of task challenge options (i.e., personalization option). It is assumed that the individuals would find the balance between their skill level and the task challenge if they could choose from easy, medium, and hard difficulty level tasks. When multiple difficulty levels are offered, individuals can personalize the difficulty level to match their skill level. This way, many individuals with different levels of skill can find the balance and satisfy the precondition of flow, and therefore, are likely to experience flow. Hence, $\mathrm{H} 5$ was developed.

H5: Students in the personalizable difficulty condition will experience a higher level of flow (control (H5a), attention focus (H5b), curiosity (H5c), and intrinsic interest (H5d)) than students in the fixed difficulty condition.

Since personalized online learning activity empowers students to choose their own learning path that is right for their skill level, it helps students manage what they learn and better perform in the given task (Pandey, 2017). Skadberg and Kimmel (2004) found that website visitors learn contents better when the skill and challenge level was balanced. Wang et al. (2011) found that animated online interactivity that allows students to personalize the input levels to generate a different visual presentation significantly enhanced students' understanding of the contents covered in the online lecture. Personalized virtual learning environment was also found to significantly improve learners' performance in final exam (Xu \& Wang, 2006). Accordingly, H6 was formulated.

H6: Students in the personalizable difficulty condition will perform better on a test than students in the fixed difficulty condition.

When the balance is achieved, learner performance and perceived hedonic and utilitarian value are expected to be also enhanced. Learners are likely to perceive an interactive tool as helpful in increasing their performance when there is personalization option. Hoffman and Novak (1996), in their seminal work, theorized the skill-challenge balance leads to positive subjective experience and exploratory mindset. These intrinsic motivations are directly connected to hedonic values. Empirical research supported the positive effect of skill-challenge balance on utilitarian and 
hedonic values. Cordova and Lepper (1996) in their experimental research found that individually personalized computer activities significantly enhanced students' engagement in learning, perceived competence, and hedonic motivation. In the experimental research, Xu and Wang (2006) found that personalized online learning materials positively influenced students' perception of system usefulness and hedonic motivation. Guo and colleagues (2016) empirically showed that the skill-challenge balance indirectly influenced perceived utilitarian and hedonic value of an online course. Thus, $\mathrm{H} 7$ was developed.

H7: Students in the personalizable difficulty condition will perceive a higher level of (H7a) utilitarian (i.e., usefulness) and (H7b) hedonic value (i.e., enjoyment) than students in the fixed difficulty condition.

Personalizable learning tools are likely to increase learner satisfaction with the learning activity. When the learner can match the task difficulty with their skill level, they are able to reduce negative emotions such as anxiety or apathy and are encouraged to engage in learning. Such an experience is likely to create positive learning experience and increase satisfaction. Online learning research found that e-learning interface with various presentation types improved learner satisfaction (Liu, Liao, \& Pratt, 2009). Özyurt and Özyurt (2015) content-analyzed 69 articles on individualized adaptive e-learning published between 2005 and 2014 and concluded that the most robust findings from the literature was the positive outcome of learner satisfaction, usability, and preferability. Out of 69, 18 studies investigated and reported significant effect of adaptive elearning (i.e., personalized teaching tools based on students' learning style) on learner satisfaction. Therefore, it is also anticipated that the skill-challenge balance positively affects user satisfaction because the flow experience leads to a positive mood and an enhanced feeling of satisfaction (Hoffman \& Novak, 1996). Therefore, H8 was formulated.

H8: Students in the personalizable difficulty condition will show a higher level of satisfaction than students in the fixed difficulty condition.

\section{Study 1}

The purpose of Study 1 was to test effects of interactivity on online learning. Study 1 is designed to test $\mathrm{H} 1$ through $\mathrm{H} 4$.

\section{Method}

Experimental stimuli development. To test the effect of interactivity on student online learning experience, a single factor, two-level (Interactivity: Yes/No), between-subjects experiment was designed. For the manipulation of interactivity, two versions of an online instructional website on color theory were developed: one with noninteractive visual contents and the other with an interactive visual learning tool that allows dynamic manipulation of visual contents. Both websites contained basic explanations for key concepts of color theory: hue, value, intensity, and color schemes. The noninteractive visual learning tool was one long webpage with written information about color theory and still images to illustrate the concepts without interactive features embedded. Thus, students scrolled down the webpage to read and learn the materials. The interactive visual learning tool was an embedded interactive flash object that presents the same content. Students could click tabs, buttons, and checkboxes to open or collapse the content and to interact with the educational contents. As students interact with the learning tool, the flash object 
modifies its content in response to the user input. See Figure 1 for sample screen shots of the interactive visual learning tool used in Study 1.

Instrument development. Eight telepresence items, adapted from Kim and Biocca (1997), were measured using 5-point Likert scales. To measure students' flow experience during the learning activity, four constructs associated with flow were measured using 5-point Likert scales. Three items were used to measure each of four flow constructs: control, attention focus, curiosity, and intrinsic interest (Nel, van Niekerk, Berthon, \& Davis, 1999). Utilitarian value, operationalized as perceived usefulness (Davis, Bagozzi, \& Warshaw, 1992), was measured using four items (e.g., "The online activities like the color theory exercise would improve my learning productivity"). Hedonic value, operationalized as perceived enjoyment (Childers, Carr, Peck, \& Carson, 2001), was measured using eight items (e.g., studying with the online activities would be fun for its own sake). Both measures used 5-point Likert scales. The inter-item reliability of measurements was checked by Cronbach's alpha and all showed good reliabilities (Cronbach's $\alpha>.70$ ). Multi-item measurements were averaged to get single scores.

Sample and procedure. Forty-five undergraduate students participated in the experiment for extra credits. This experiment was done in a lab setting to minimize the effect of other miscellaneous environmental factors (e.g., technology types, computer specification, internet speed, time spent, etc.) on dependent measures. In the computer lab, students were asked to learn the materials by exploring the assigned website for 10 minutes. Students were randomly assigned to either the interactive $(N=24)$ or the noninteractive site $(N=21)$. After the 10 minutes, students were given a survey questionnaire which included items measuring flow experience and telepresence while browsing the site, and utilitarian and hedonic values of using the online learning tool. Students were also asked to provide demographic information (age, ethnicity, year in college) and previous experience with online learning tools. Upon the completion of the activity, students completed a short quiz on color theory consisting of six questions. The quiz scores were used to measure actual student learning after the completion of the online activity.

\section{Results}

Description of participants. Participants' $(N=45)$ mean age was 20.73 , with a range of 18 to 26. Hispanic American was the single largest group accounting for about $35.6 \%$ of participants. Other participants were Caucasian-American (28.9\%), African-American (8.9\%), Asian/Asian-American (17.8\%), and other (6.7\%). Most participants were sophomores (46.7\%) and juniors $(37.8 \%)$. The number of freshmen $(4.4 \%)$ and seniors $(8.9 \%)$ was small. The majority ( $80 \%$ of participants) claimed that they have previously used online learning tools, such as a study guide or other online activities in four classes or more.

Hypotheses testing. Multivariate analysis of variance (MANOVA) was used to test the effects of interactivity on various dependent measures. The results showed a significant multivariate main effect of interactive online activity on dependent measures $(F[8,36]=5.426, p$ $<.0001)$. Univariate analysis of variance (ANOVA) was also analyzed to test each hypothesis proposed in Study 1 as follows. 


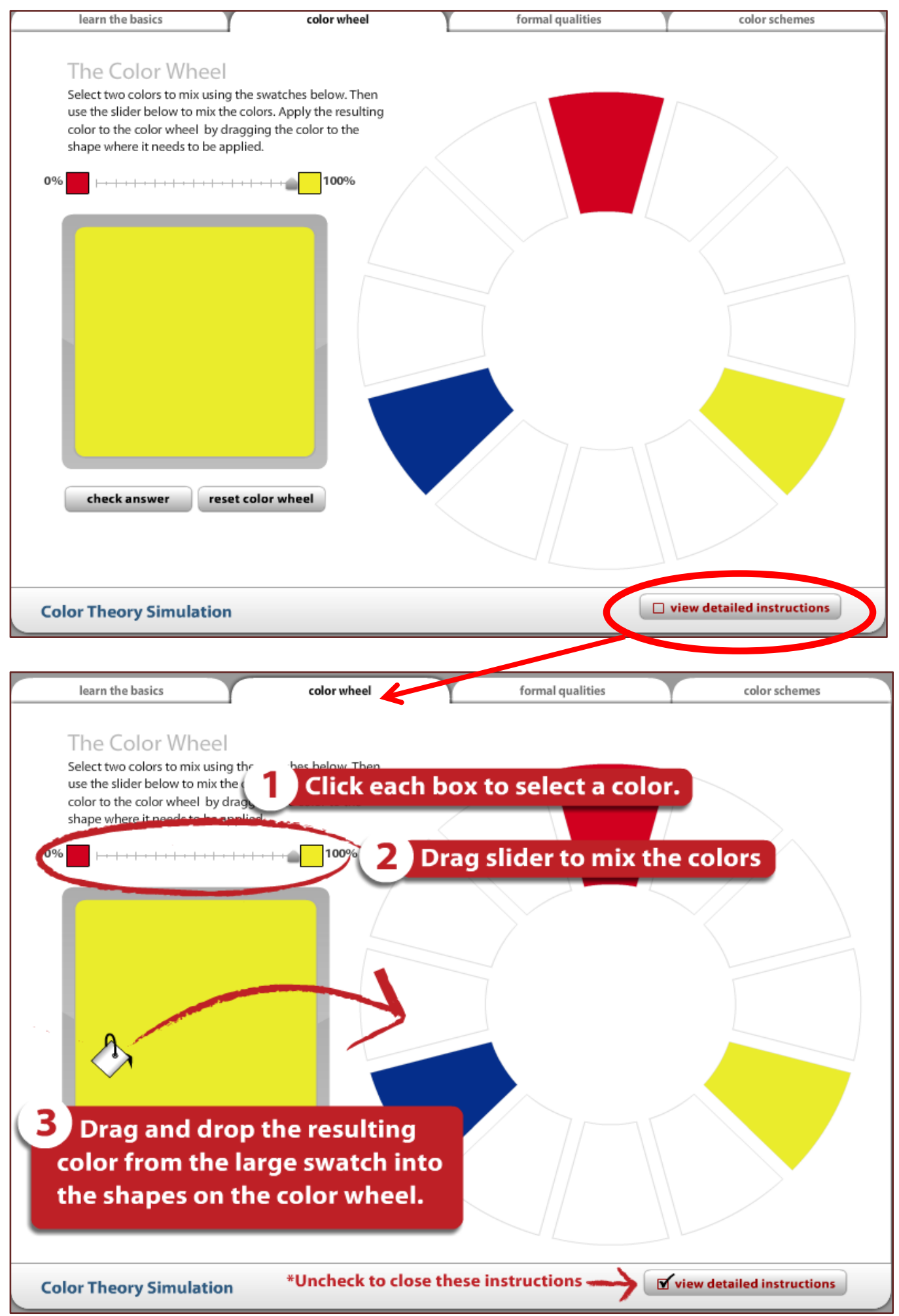

Figure 1. Sample screenshot of the interactive visual learning tool used in Study 1. 
Hypothesis 1. ANOVA found a significant main effect of interactivity on telepresence ( $F$ $[1,43]=15.729, p<.0001)$. Students in the interactive condition showed significantly higher mean scores for telepresence $(M=2.99, S D=.983)$ than those in the noninteractive condition $(M=2.02$, $S D=.570)$. The result indicates that interactive visual imageries used in the online activity contributed to telepresence. Thus, H1 was supported.

Hypothesis 2. ANOVA revealed a significant main effect of interactivity on attention focus $(F[1,43]=10.608, p<.001)$, curiosity $(F[1,43]=14.053, p<.001)$, and intrinsic interest $(F[1$, $43]=26.969, p<.0001)$, supporting $\mathrm{H} 2 \mathrm{~b}, \mathrm{H} 2 \mathrm{c}$, and $\mathrm{H} 2 \mathrm{~d}$. Students in the interactive condition showed significantly higher mean scores than those in the noninteractive condition for attention focus (interactive: $M=3.34, S D=.726$, noninteractive: $M=2.60, S D=.807$ ), curiosity (interactive: $M=3.88, S D=.679$, noninteractive: $M=3.13, S D=.654$ ), and intrinsic interest (interactive: $M=4.03, S D=.629$, noninteractive: $M=3.05, S D=.635$ ). However, control did not show a significant difference between groups, rejecting $\mathrm{H} 2 \mathrm{a}$. Although the difference was not statistically significant, mean scores showed the direction consistent with our prediction (interactive: $M=3.68, S D=.641$ vs. noninteractive: $M=3.41, S D=.893$ ).

Hypothesis 3. A significant main effect of interactivity on student's actual performance in the test was also found $(F[1,43]=35.110, p<.0001)$. An inspection of the cell means revealed that students in the interactive condition performed significantly better in the quiz (interactive: $M$ $=5.33, S D=1.049$ vs. noninteractive: $M=3.38, S D=1.161$ ). Thus, $\mathrm{H} 3$ was supported. The results indicate that the interactive visual learning tool used for the online activity could enhance student learning.

Hypothesis 4. ANOVA revealed a significant main effect of interactivity on utilitarian ( $F$ $[1,43]=18.161, p<.0001)$ and hedonic value $(F[1,43]=7.334, p<.01)$. An inspection of the cell means revealed that students in the interactive condition perceived the online activity more useful and enjoyable (utilitarian: $M=4.50, S D=.659$, hedonic: $M=4.01, S D=.601$ ) than those in the noninteractive condition (utilitarian: $M=3.68, S D=.628$, hedonic: $M=3.51, S D=.619$ ). Thus, H4a and H4b were supported.

\section{Study 2}

The purpose of Study 2 was to test effects of skill and challenge balance on flow and learning. Study 2 is designed to test $\mathrm{H} 5$ through $\mathrm{H} 8$.

\section{Method}

Experimental stimuli development. To examine the effects of skill-challenge balance on flow experience, a single factor, 2-level (personalizable difficulty vs. fixed difficulty) betweensubjects design was used. It is assumed that student skill level and task difficulty would be more likely to match when the students have an option to personalize the level of task difficulty. Therefore, two interactive visual learning tools, one with three personalizable difficulty levels and the other with a fixed difficulty level, were developed.

The learning tools had multiple tabs for providing concepts and theory explanation and for application activities. Both tools contained the identical theory information tab that provided written information on the basic color theory with proper visual examples and interactive features to assist understanding of the basic concepts. Both learning tools presented an interactive activity tab that was designed to help students understand various color relationships using Munsell color 
chart. Students were able to drag and drop color chips in the correct order on a two-dimensional chart with the $\mathrm{x}$-axis representing intensity or chroma and the $\mathrm{y}$-axis representing value of a hue. The activity could be repeated for four different hues and students could select one hue at a time.

Two learning tools differed in the availability of difficulty selection options. For the tool with the personalizable option, students were able to choose a difficulty level out of three options (i.e., easy, medium, and hard) using a drop-down menu. The easy, medium, and hard levels (see Figure 2 for three difficulty levels) presented 8-15, 18-28, and 61-93 color swatches to be placed in the chart, respectively. The exact number of color swatches varied based on value and intensity of the selected hue. The activity with the fixed difficulty option presented the medium difficulty level only with 18-28 color swatches (see Figure 2 for the medium difficulty option).

Sample and procedure. One hundred and forty undergraduate students from four sections of the same course taught in two large universities participated in the experiment for extra credits. In a computer lab, students were randomly assigned to one of the experimental conditions (personalizable $[N=72]$ vs. fixed difficulty $[N=68]$ ) and were asked to learn the materials and explore the online activity for 20 minutes. Students were directed to view the basic information tab first to learn about the color theory, and then to complete the interactive online activity through which students created a value/intensity color chart. Upon the completion of the activity, students were asked to complete a survey questionnaire online, which included items measuring four flow constructs, utilitarian and hedonic values of using such activities, and satisfaction. Students $(N=$ 50) from one university also completed a short test to measure the effect of skill-challenge balance on learning. Test scores were used to examine students' actual performance after the activity. Students in the other university could not complete the test due to the limitation of course schedule. Demographic information (age, ethnicity, year in college) and four questions regarding previous experience with the online learning tools were also collected.

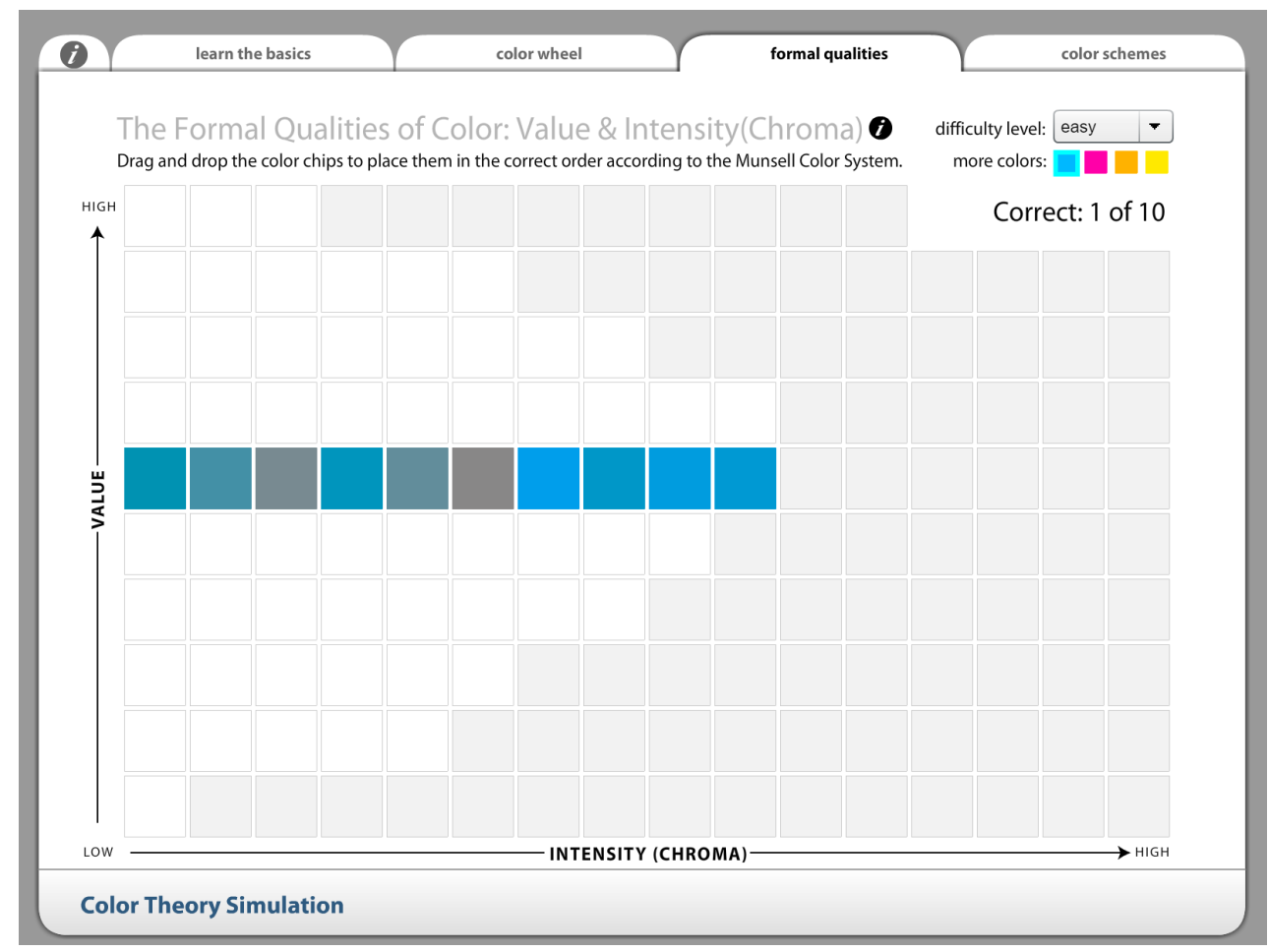

Figure 2a. Three difficulty levels manipulated in Study 2: Easy 
The Role of an Interactive Visual Learning Tool and its Personalizability in Online Learning: Flow Experience
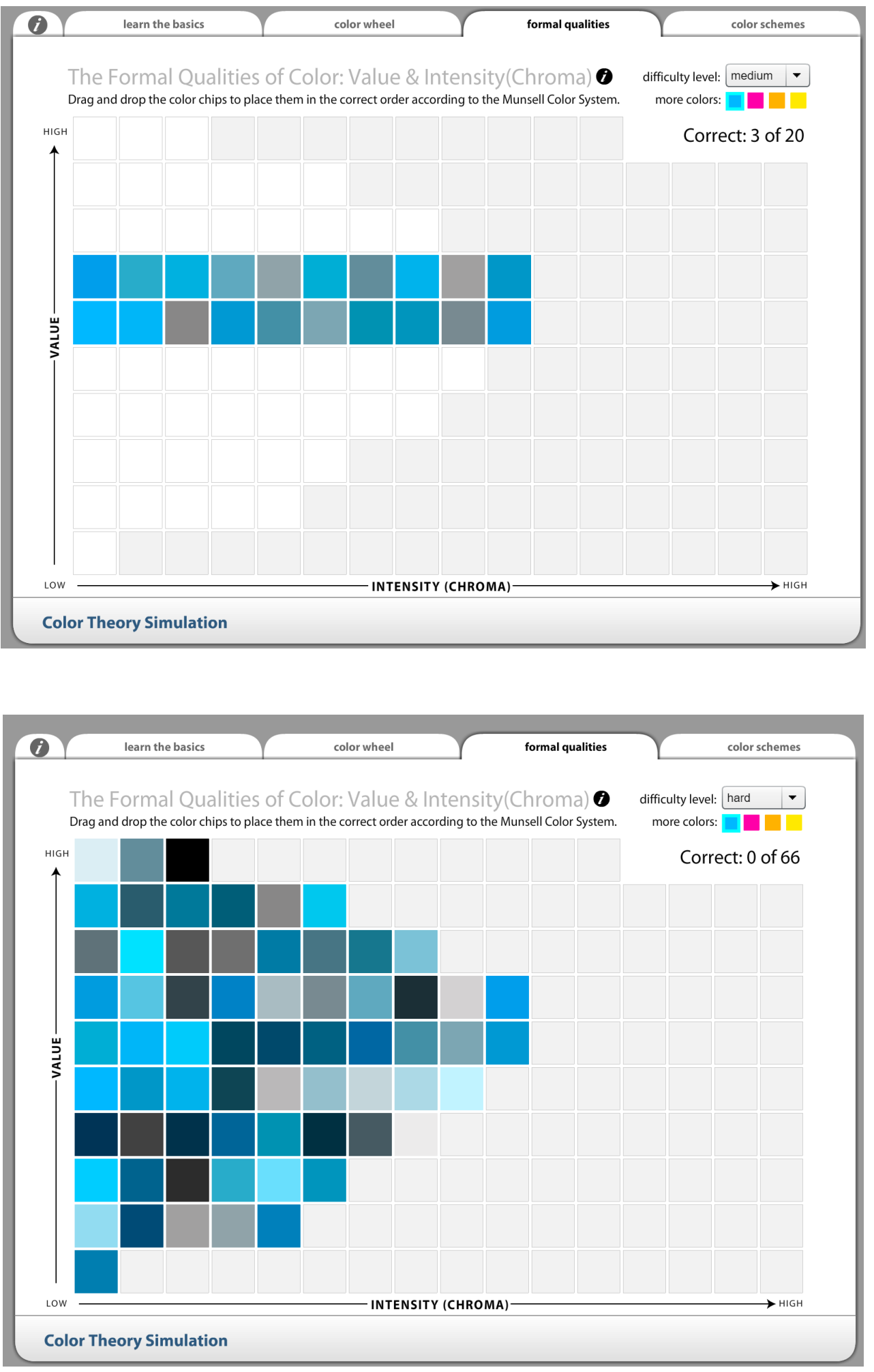

Figure 2b. Three difficulty levels manipulated in Study 2: Medium (top), Hard (bottom) 
Instrument development. The same items used in Study 1 were used to measure flow experience and utilitarian/hedonic values. Three overall satisfaction items (e.g., Do you like the online activities like XXX?) were added to Study 2 and measured using 5-point Likert-type scale (Not at all to Very much). The inter-item reliability of measurements was checked by Cronbach's alpha and all showed good reliabilities (Cronbach's $\alpha>.702$ ). A multi-item measurement was averaged to get a single score to test hypotheses.

\section{Results}

Description of participants. The mean age of participants $(N=140)$ was 21.5 , with a range of 18 to 39. Caucasian American was the single largest group accounting for about $68.6 \%$ of participants followed by Asian American (12.9\%), Hispanic American (10.7\%), African American (2.1\%), and other (5.7\%). Most participants were seniors (66.4\%), with about equal numbers of juniors (15\%) and sophomores (14.3\%). Freshmen (4.3\%) were small. The majority (over $70 \%$ ) of participants had often used the online learning tools to obtain course information (e.g., lecture note, grades) and to use for the group discussion.

Hypotheses testing. Multivariate analysis of variance (MANOVA) was used to test the effects of personalizable difficulty level option on various dependent measures. The results showed a significant multivariate main effect of personalizable difficulty-level option on dependent measures $(F[7,125]=2.292, p<.05)$.

Hypothesis 5. Univariate analysis of variance (ANOVA) revealed a significant main effect of personalizable difficulty level option in the interactive activity on curiosity $(F[1,131]=4.823$, $p<.05)$ and intrinsic interest $(F[1,131]=10.09, p<.005)$, supporting H5c and H5d. Students in the condition with three personalizable difficulty-level option showed significantly higher mean scores for curiosity (personalizable: $M=4.02, S D=.644$ vs. fixed: $M=3.74, S D=.809$ ) and intrinsic interest (personalizable: $M=4.13, S D=.624$ vs. fixed: $M=3.75, S D=.766$ ) than those in the fixed condition. However, control and attention focus did not show a significant difference between groups, rejecting $\mathrm{H} 5 \mathrm{a}$ and $\mathrm{H} 5 \mathrm{~b}$.

Hypothesis 6. The result of ANOVA revealed no significant difference between two groups in terms of actual test scores $(F[1,48]=2.97, p=.09)$, rejecting H6. This result suggests that the availability of personalizable difficulty-level option in the interactive online activity did not influence students' actual performance on the test.

Hypothesis 7. ANOVA results showed a significant main effect of personalizable difficulty level option in the online activity on hedonic value $(F[1,131]=6.048, p<.05)$ but not significant on utilitarian value $(F[1,131]=3.272, p=.073)$. Cell means also revealed that students perceived the interactive online activity with the personalizable difficulty level option more enjoyable $(M=$ $4.05, S D=.502)$ than the activity with the fixed option $(M=3.80, S D=.677)$. Thus, only H7b was supported.

Hypothesis 8. A significant main effect of personalizable difficulty level option on student's satisfaction toward the interactive online learning activity was also found $(F[1,131]=$ $4.839, p<.05)$. This indicates that students found the interactive online activity with personalizable difficulty level option more favorable than the one with the fixed option (personalizable: $M=4.42$, $S D=.574$ vs. fixed: $M=4.15, S D=.819)$. Therefore, $\mathrm{H} 8$ was supported. 
Table 1

Mean (M) and Standard Deviation (SD) Scores for Different Conditions in Study 1 and Study 2

\begin{tabular}{|c|c|c|c|c|c|c|c|c|}
\hline \multirow[b]{3}{*}{ Dependent Variables } & \multicolumn{4}{|c|}{ Study 1} & \multicolumn{4}{|c|}{ Study 2} \\
\hline & \multicolumn{2}{|c|}{$\begin{array}{c}\text { No } \\
\text { Interactivity }\end{array}$} & \multicolumn{2}{|c|}{ Interactivity } & \multicolumn{2}{|c|}{$\begin{array}{c}\text { Fixed } \\
\text { Difficulty Level }\end{array}$} & \multicolumn{2}{|c|}{$\begin{array}{c}\text { Three } \\
\text { Difficulty Levels }\end{array}$} \\
\hline & $\underline{\mathrm{M}}$ & $\underline{\mathrm{SD}}$ & $\underline{\mathrm{M}}$ & $\underline{\mathrm{SD}}$ & $\underline{\mathrm{M}}$ & $\underline{\mathrm{SD}}$ & $\underline{M}$ & $\underline{\mathrm{SD}}$ \\
\hline Control & $3 . \overline{4} 1$ &.$\overline{893}$ & $3 . \overline{6} 8$ &.$\overline{641}$ & 3.90 &.$\overline{682}$ & 3.89 & .644 \\
\hline Attention Focus & 2.60 & .807 & 3.34 & .726 & 3.33 & .878 & 3.47 & .707 \\
\hline Curiosity & 3.13 & .654 & 3.88 & .679 & 3.74 & .809 & 4.02 & .644 \\
\hline Intrinsic Interest & 3.05 & .635 & 4.03 & .629 & 3.75 & .766 & 4.13 & .624 \\
\hline Intrinsic Motivation & 3.51 & .619 & 4.01 & .601 & 3.80 & .677 & 4.05 & .502 \\
\hline Extrinsic Motivation & 3.68 & .628 & 4.50 & .659 & 4.21 & .804 & 4.45 & .734 \\
\hline
\end{tabular}

Note. All items were measured using 5-point Likert scale.

\section{Discussion and Conclusion}

\section{Contribution of the Study}

The current study empirically investigated effects of the interactive visual learning tools on student learning experience and performance through two experiments. The findings of the study contribute to the literature of human-computer interaction in the context of online learning. Based on the theory of flow, the current study highlighted the potential of the interactive visual learning tools for teaching visual contents online. The study is also a response to a call for empirical testing of human-computer interaction effect on student online learning (Wei et al., 2015). Additionally, this study makes contribution to the literature of e-learning by testing two important characteristics of online learning tools, interactivity, and personalizable options for skill-challenge balance, that positively lead to flow experience, learner perception, and performance. It is noteworthy that this study provides evidence for causal effects of interactivity and personalization through controlled experiments while many studies inferred the effects through correlations between learner's self-reported perception and academic performances (e.g., Chou et al., 2010; Etemad-Sajadi, 2016; Wei et al., 2015).

\section{Effect of Interactivity on Telepresence, Flow, and Learning}

The purpose of Study 1 was to investigate the effect of the interactive visual learning tools on students' learning process. Similar to the prior research (Lim \& Ayyagari, 2018) suggesting interactivity as a major antecedent of telepresence in the context of e-commerce setting, this study demonstrates the significant effect of interactivity on telepresence in the online learning environment. This result demonstrates the critical role of dynamic, real-time interactivity in improving students' learning by reducing awareness of physical surroundings.

Consistent with previous research (Esteban-Millat et al., 2014; Rodriguez-Ardura \& Meseguer-Artola, 2016), the result of this study also supports that the interactive visual learning tools augmented students' flow experience in the context of an e-learning environment. The result reveals that students who used the interactive visual learning tools experienced a higher level of flow (attention focus, curiosity, intrinsic interest) than those who used the noninteractive one. This 
implies that interactive visual learning tools can facilitate student's active learning process by increasing attention, curiosity, and interest about the online activity. Therefore, to enrich student learning experience in the online learning environment, it is of greatest importance to incorporate interactivity by means of dynamic visualization into online instructional materials. This can be more beneficial when students learn abstract concepts, particularly in the context of online learning environment where students easily lose their attention and interest on lecture materials.

This study also confirms that the interactive visual learning tools contribute to learning, which was evidenced by higher test scores for the interactive group than for the noninteractive group. Previously published studies have reported mixed findings related to effects of interactive learning tools on performance. Some found supporting evidence for positive effects of interactive learning tools (e.g., Sharp \& Hamil, 2018) while others failed to confirm the effect (Wei et al., 2015). According to Wang et al. (2011), this inconsistency might be because levels or types of learning examined in previous studies were not consistent. Wang et al. (2011) found that animated interactivity is more effective for the intermediate level of learning (i.e., understanding concepts) than for the lowest (i.e., remembering) or highest level of learning (i.e., high level applying). Since the current study employed the interactive activity to help students understand the concept of color theory, the learning activities students were engaged in can be in the intermediate level of learning. Thus, our result corroborates Wang et al.'s (2011) findings. When developing an interactive online learning activity, online content developers or instructors are necessary to consider levels or types of learning students should achieve.

\section{Effect of Personalized Interactivity on Flow and Satisfaction}

Study 2 tested how the interactive online activity with personalization (i.e., three difficulty level options to achieve skill-challenge balance) influences students' learning experience. As expected, students experienced significantly higher level of curiosity and interest about the online activity when three difficulty-level options were available than when one fixed option was available. Once the balance between students' skill level and task challenge in the online activity is achieved, students tend to experience higher level of flow elicited by higher curiosity and interest about the online activity. This result is consistent with the previous research (Guo et al., 2016) that found the significant impact of perceived balance between challenge and skill level on flow experience in online learning.

However, inconsistent with the hypotheses, the influence of the skill-challenge balance on level of attention focus was not significant. The effect could have been minimal because both conditions presented very interactive tools with dynamic visualizations. When compared with the noninteractive group in Study 1, both personalizable and fixed difficulty groups in Study 2 experienced fairly high level of attention focus (see Table 1 for mean scores). It is possible that the availability of online interactivity has a stronger effect on level of attention focus than the availability of personalizable difficulty level options. In addition, Engeser and Rheinberg (2008) found that perceived importance of the task moderates effects of the skill-challenge balance on flow experience. Therefore, it is possible that when the students feel the task is important, the effects of the balance may be attenuated because their goal to achieve the end outcome predominantly determines their level of flow.

Although no significant difference was found in terms of test scores between two groups, students' overall satisfaction with the online activity was significantly higher for the group with personalizable difficulty-level option. This finding is in line with results of a previous study that 
reported perceived balance of challenge and skill only affects satisfaction but not perceived learning of subject matter or actual performance (Rossin et al., 2009). Rossin et al. (2009) argued that this might be because of an intrinsic reward associated with tasks performed. As demonstrated earlier in the current study, personalized difficulty options induced higher curiosity and interest for students and influenced satisfaction. The results imply that the online task performed serves as its own intrinsic reward (i.e., satisfaction) at the moment of first use and therefore no need for an extrinsic reward (e.g., test score improvement) to continue adopting the task. Wei et al. (2015) claimed that once the task is adopted and used frequently, performance score will be improved as well.

\section{Control in Online Learning}

For both Study 1 and 2, effects of interactivity and skill-challenge balance on control were not supported. Although mean scores showed the direction consistent with our prediction, control was not statistically different between two experimental conditions in Study 1. Similarly, the mean scores of control for the personalizable difficulty group and the fixed difficulty group were statistically same. Control is a feeling that one is in control of their own action and the interactions at the moment (Koufaris, 2002) and is an important element of flow experience. However, it could be that the students in all conditions felt equally in control of their actions because the context of the experiment was online learning and they were left to explore the learning tools on their own. Regardless of their experimental conditions, whether they were using the interactive tool or not, or working on the activity with the personalizable difficulty levels or not, the students were given the time, space, and the computer to play with the learning tool. Therefore, in the context of online learning, control may be not as important as some other dimensions of flow. Consistent with this logic, Fong et al. (2015), after analyzing 46 studies specifically investigating the relationships between skill-challenge balance and flow, concluded that the skill-challenge balance effects on flow is weakest in work or education contexts (vs. leisure or personal contexts). Fong et al. (2015) also noted the skill-challenge balance seemed to be more important for older populations (i.e., aged 30 and over). This implies that personalization effects on feeling of control may be stronger for older people. Because our study sample is a younger group of students in their early 20 s, the effects could have been attenuated.

\section{Hedonic and Utilitarian Values}

Consistent with previous research (Cheng, 2013a), the result of Study 1 supported that students exposed to the interactive visual learning tools perceived the online activity more useful (utilitarian value) and enjoyable (hedonic value) than those exposed to noninteractive visual learning tools. The result confirms the critical role of human-computer interactivity in enhancing students' hedonic and utilitarian motivation to use online learning tools. It is important for online instructional designers to utilize interactive online contents that are more useful and enjoyable, which will cultivate learners' involvement in learning.

As demonstrated in Study 2, students perceived higher level of hedonic value about the online activity when they were able to balance the task-challenge level with their own skill level. Students tend to enjoy the online learning activity more when they have personalizable options to choose the challenge level than when they have no option. This result supports Cordova and Lepper (1996) who found the significant impact of personalization and choice on students' perceived hedonic value (i.e., enjoyment) in the process of learning. Both Studies 1 and 2 demonstrate that interactivity and personalizability play important roles in motivating students hedonically. 
Although no statistically significant difference was found in terms of perceived utilitarian value, as revealed in the cell mean comparisons (see Table 1), students were likely to perceive the online activity with personalizable options more useful than the one with the fixed option. More importantly, both conditions showed high usefulness mean scores, indicating that students tend to perceive the interactive online activity, whether it was personalizable or not, highly useful and valuable for their learning productivity. Similarly, Wang et al. (2011) found that three levels of animated interactivity (i.e., low to high interactivity) did not change students' perceived usefulness of the activity used. More importantly, students in all three interactivity treatment groups in Studies 1 and 2 showed higher perception scores than the control group (i.e., no interactivity group in Study 1). Therefore, it is possible that the availability of dynamic visual interactivity contributes more to students' perceived utilitarian value than that of personalization options (or higher level of interactivity). Results from two experiments suggest that online interactivity is a major determinant of both hedonic and utilitarian values and achieving a skill-challenge balance with personalizable options is also considered important for perceived hedonic value. This implies that as long as dynamic interactivity exists in the online learning context, students would perceive such activities as useful and enjoyable for e-learning process. However, for engagement and intrinsic motivation, hedonic value can be particularly important. Therefore, online course designers are advised to offer appropriate task challenge options based on learners' inherent skill level to enhance their interest in online learning process.

\section{Limitations and Future Studies}

Although this study contributes to the understanding of students' learning process established by flow experience in the context of online learning environment by employing real online activities in two experimental studies and by measuring actual test scores upon the completion of each activity, there are a few limitations to be addressed. To minimize effects of other confounding factors (e.g., internet access/speed, computer specification and types, etc.) on dependent measures, both studies were done in the lab setting with limited time given to students. Therefore, interpretation and generalizability of the findings should be done with caution. It is possible that results of this study would be slightly different from the current study when various personal and situational factors (e.g., computer or mobile devices used, internet speed, time spent on activity, other environmental factors, etc.) are introduced. Thus, replications of the current study in various settings such as an online experiment in the future are necessary to understand combined effects of various factors. Also, the current study used two versions of a single content learning object to test the interactivity and personalization effects. Conducting studies with similar online learning materials will be meaningful to test the robustness of the effects across multiple interactive learning tools. In future studies, it is also important to examine how personal differences in learning styles affect students' performance and responses to this type of interactive

online learning activity, particularly with customizable options, because not everyone learns in the same way.

\section{Author Note}

Correspondence related to this paper should be addressed to Young Ha, California State University, Long Beach, young.ha@csulb.edu 


\section{References}

Allen, I. E., Seaman, J., Poulin, R., \& Straut, T. T. (2016, February). Online report card: Tracking online education in the United States. Online Learning Survey. https://onlinelearningsurvey.com/reports/onlinereportcard.pdf

Babin, B. J., Darden, W. R., \& Griffin, M. (1994). Work and/or fun: Measuring hedonic and utilitarian shopping value. Journal of Consumer Research, 20(4), 644-656.

Carroll, F., \& Kop, R. (2016). Colouring the gaps in learning design: Aesthetics and the visual in learning. International Journal of Distance Education Technologies, 14(1), 92-103.

Carrozzino, M., \& Bergamasco, M. (2010). Beyond virtual museum: Experiencing immersive virtual reality in real museums. Journal of Cultural Heritage, 11(4), 452-458.

Chang, H. H., \& Wang, I. C. (2008). An investigation of user communication behavior in computer mediated environments. Computers in Human Behavior, 24(5), 2336-2356.

Chen, R. (2018, March 11). How to cut high dropout rates of online courses. eLearning Industry. https://elearningindustry.com/dropout-rates-of-online-courses-cut-high

Chen, B., Chang, Y. H., Ouyang, F., \& Zhou, W. (2018). Fostering student engagement in online discussion through social learning analytics. The Internet and Higher Education, 37, 2130.

Cheng, Y. (2013a). Roles of interactivity and usage experience in e-learning acceptance: a longitudinal study. International Journal of Web Information Systems, 10(1), 2-23.

Cheng, Y. (2013b). Exploring the roles of interaction and flow in explaining nurses' e-learning acceptance. Nurse Education Today, 33(1), 73-80.

Childers, T. L., Carr, C. L., Peck, J., \& Carson, S. (2001). Hedonic and utilitarian motivations for online retail shopping behavior. Journal of Retailing, 77(4), 511-535.

Cho, M. H., \& Kim, B. J. (2013). Students' self-regulation for interaction with others in online learning environments. The Internet and Higher Education, 17, 69-75.

Choi, D. H., Kim, J., \& Kim, S. H. (2007). ERP training with a web-based electronic learning system: The flow theory perspective. International Journal of Human-Computer Studies, $65,223-243$.

Chou, C. (2003). Interactivity and interactive functions in web-based learning systems: A technical framework for designers. British Journal of Educational Technology, 34(3), 265-279.

Chou, C., Peng, H., \& Chang, C. Y. (2010). The technical framework of interactive functions for course-management systems: Students' perceptions, uses, and evaluations. Computers \& Education, 55(3), 1004-1017.

Cordova, D. I., \& Lepper, M. R. (1996). Intrinsic motivation and the process of learning: Beneficial effects of contextualization, personalization, and choice. Journal of Educational Psychology, 88(4), 715-730. 
Coyle, J., Mendelson, A., \& Kim, H. (2008). The effects of interactive images and goal-seeking behavior on telepresence and site ease of use. Journal of Website Promotion, 3(1/2), 3961.

Csikszentmihalyi, M. (1990). Flow: The psychology of optimal experience. Harper \& Row.

Csikszentmihalyi, M., Abuhamdeh, S., \& Nakamura, J. (2005). Flow. In A. J. Elliot \& C. S. Dweck (Eds.), Handbook of competence and motivation (pp. 598-608). Guilford.

Csikszentmihalyi, M., \& Csikszentmihalyi, I. (1988). Optimal experience: Psychological studies of flow in consciousness. Cambridge University Press.

Davis, F. D., Bagozzi, R. P., and Warshaw, P. R. (1992). Extrinsic and intrinsic motivation to use computers in the workplace. Journal of Applied Social Psychology, 22(14), 1111-1132.

Domagk, S., Schwartz, R. N., \& Plass, J. L. (2010). Interactivity in multimedia learning: An integrated model. Computers in Human Behavior, 26(5), 1024-1033.

Jasmini, V. (2017, August 13). Online learning statistics and trends. eLearning Industry. https://elearningindustry.com/online-learning-statistics-and-trends

Engeser, S., \& Rheinberg, F. (2008). Flow, performance and moderators of challenge-skill balance. Motivation and Emotion, 32(3), 158-172.

Esteban-Millat, I., Martinez-Lopez, F. J., Huertas-Garcia, R., Meseguer-Artola, A., \& Rodriguez-Ardura, I. (2014). Modeling students' flow experiences in an online learning environment. Computers \& Education, 71, 111-123.

Etemad-Sajadi, R. (2016). The impact of online real-time interactivity on patronage intention: The use of avatars. Computers in Human Behavior, 61, 227-232.

Evans, C., \& Gibbons, N. J. (2007). The interactivity effect in multimedia learning. Computers \& Education, 49(4), 1147-1160.

Evans, C., \& Sabry, K. (2003). Evaluation of interactivity of web-based learning systems: Principles and process. Innovations in Education and Teaching International, 40(1), 8999.

Fong, C. J., Zaleski, D. J., \& Leach, J. K. (2015). The challenge-skill balance and antecedents of flow: A meta-analytic investigation. The Journal of Positive Psychology, 10(5), 425-446.

Fortin, D., \& Dholakia, R. (2005). Interactivity and vividness effects on social presence and involvement with a web-based advertisement. Journal of Business Research, 58(3), 387396.

Friedman, J. (2018, January 11). Study: More students are enrolling in online courses. U.S. News and World Report. https://www.usnews.com/higher-education/onlineeducation/articles/2018-01-11/study-more-students-are-enrolling-in-online-courses

Fullagar, C. J., Knight, P. A., \& Sovern, H. S. (2013). Challenge/skill balance, flow, and performance anxiety. Applied Psychology, 62(2), 236-259.

Guo, Z., Xiao, L., van Toorn, C., Lai, Y., \& Seo, C. (2016). Promoting online learners' continuance intention: An integrated flow framework. Information \& Management, 53, 279-295. 
Hoffman, D. L. \& Novak, T. P. (1996). Marketing in hypermedia computer-mediated environments: Conceptual foundations. Journal of Marketing, 60(July), 50-68.

Hoffman, D. L., \& Novak, T. P. (2009). Flow online: Lessons learned and future prospects. Journal of Interactive Marketing, 23, 23-34.

Huang, M-H. (2003). Designing website attributes to induce experiential encounters. Computers in Human Behavior, 19, 425-442.

Karageorgakis, T. (2018, April 7). The importance of interactivity in eLearning programs. eLearning Industry. https://elearningindustry.com/interactivity-in-elearning-programsimportance

Kent, C., Laslo, E., \& Rafaeli, S. (2016). Interactivity in online discussions and learning outcomes. Computers \& Education, 97, 116-128.

Kim, T., \& Biocca, F. (1997). Telepresence via television: Two dimensions of telepresence may have different connections to memory and persuasion. Journal of Computer-Mediated Communication, 3(2). https://doi.org/10.1111/j.1083-6101.1997.tb00073.x

Koufaris, M. (2002). Applying the technology acceptance model and flow theory to online consumer behavior. Information Systems Research, 3(2), 205-223.

Kucuk, S., \& Richardson, J. C. (2019). A structural equation model of predictors of online learners' engagement and satisfaction. Online Learning, 23(2), 196-216.

Li, H., Daugherty, T., \& Biocca, F. (2002). Impact of 3-D advertising on product knowledge, brand attitude, and purchase intention: The mediating role of presence. Journal of Advertising, 31(3), 43-58.

Liaw, S. S. (2008). Investigating students' perceived satisfaction, behavioral intention, and effectiveness of e-learning: A case study of the Blackboard system. Computers \& Education, 51(2), 864-873.

Liaw, S. S., \& Huang, H. M. (2013). Perceived satisfaction, perceived usefulness and interactive learning environment as predictors to self-regulation in e-learning environments. Computers \& Education, 60(1), 14-24.

Lim, J., \& Ayyagari, R. (2018). Investigating the determinants of telepresence in the e-commerce setting. Computers in Human Behavior, 85, 360-371.

Liu, S. H., Liao, H. L., \& Pratt, J. A. (2009). Impact of media richness and flow on e-learning technology acceptance. Computers \& Education, 52(3), 599-607.

Low, A. L., Low, K. L. T., \& Koo, V. C. (2003). Multimedia learning systems: A future interactive educational tool. The Internet and Higher Education, 6(1), 25-40.

Luo, N., Zhang, M., \& Qi, D. (2017). Effects of different interactions on students' sense of community in e-learning environment. Computers \& Education, 115, 153-160.

Meyer, A., Klingenberg, K., \& Wilde, M. (2016). The benefits of mouse keeping-An empirical study on students' flow and intrinsic motivation in biology lessons. Research in Science Education, 46, 79-90.

Meyer, K. A., \& Jones, S. J. (2013). Do students experience flow conditions online? Journal of Asynchronous Learning Networks, 17(3), 1-12. 
Moreillon, J. (2015). Increasing interactivity in the online learning environment: Using digital tools to support students in socially constructed meaning-making. TechTrends, 59(3), 4147.

Nel, D., van Niekerk, R., Berthon, J., \& Davis, T. (1999). Going with the flow: Web sites and customer involvement. Internet Research, 9(2), 109-116.

Oria, V. (2017, June 7). Lowering online student dropout rates. Inside Higher Ed. https://www.insidehighered.com/digital-learning/views/2017/06/07/tools-lower-studentdropout-rates

Ou, C., Joyner, D. A., \& Goel, A. K. (2019). Designing and developing video lessons for online learning: A seven-principle model. Online Learning, 23(2), 82-104.

Oudeyer, P-Y., Gottlieb, J., \& Lopes, M. (2016). Intrinsic motivation, curiosity, and learning: Theory and applications in educational technologies. Progress in Brain Research, 229, 257-284.

Özyurt, Ö., \& Özyurt, H. (2015). Learning style based individualized adaptive e-learning environments: Content analysis of the articles published from 2005 to 2014. Computers in Human Behavior, 52, 349-358.

Paechter, M., Maier B., \& Macher, D. (2010). Students' expectations of, and experiences in elearning: Their relation to learning achievements and course satisfaction. Computers \& Education, 54(1), 222-229.

Pandey, A. (2017, May 30). How personalized e-learning engages learners-featuring a case study. eLearning Industry. https://elearningindustry.com/personalized-elearning-engageslearners-featuring-case-study

Park, J. (2011). Design education online: Learning delivery and evaluation. The International Journal of Art \& Design Education, 30(2), 176-187.

Rodriguez-Ardura, I., \& Meseguer-Artola, A. (2016). E-learning continuance: The impact of interactivity and the mediating role of imagery, presence, and flow. Information \& Management, 53, 504-516.

Rossin, D., Ro, Y. K., Klein, B. D., \& Guo, Y. M. (2009). The effects of flow on learning outcomes in an online information management course. Journal of Information Systems Education, 20(1), 87-98.

Skadberg, Y. X., \& Kimmel, J. R. (2004). Visitors' flow experience while browsing a web site: Its measurement, contributing factors, and consequences. Computers in Human Behavior, $20,403-422$.

Sharp, L. A., \& Hamil, M. (2018). Impact of a web-based adaptive supplemental digital resource on student mathematics performance. Online Learning, 22(1), 81-92.

Sheiter, K., Schubert, C., Schuler, A., Schmidt, H., Zimmermann, G., Wassermann, B., Krebs, M. C., \& Eder, T. (2019). Adaptive multimedia: Using gaze-contingent instructional guidance to provide personalized processing support. Computers \& Education, 139, 3147. 
Steuer, J. (1992). Defining virtual reality: Dimensions determining telepresence. Journal of Communication, 42(4), 73-93.

Sun, J-N., \& Hsu, Y-C. (2013). Effect of interactivity on learner perceptions in web-based instruction. Computers in Human Behavior, 29(1), 171-184.

Van der Heijden, H. (2004). User acceptance of hedonic information systems. MIS Quarterly, $28,695-704$.

Wang, P-Y., Vaughn, B. K., \& Liu, M. (2011). The impact of animation interactivity on novices' learning of introductory statistics. Computers \& Education, 56, 300-311.

Wei, H. C., Peng, H., \& Chou, C. (2015). Can more interactivity improve learning achievement in an online course? Effects of college students' perception and actual use of a coursemanagement system on their learning achievement. Computers \& Education, 83, 10-21

Xu, D., \& Wang, H. (2006). Intelligent agent supported personalization for virtual learning environments. Decision Support Systems, 42(2), 825-843.

Yeh, Y. C., Rega, E. M., \& Chen, S. Y. (2019). Enhancing creativity through aestheticsintegrated computer-based training: The effectiveness of a FACE approach and exploration of moderators. Computers \& Education, 139, 48-64. 